\title{
A comparative assessment of two different debris flow propagation approaches - blind simulations on a real debris flow event
}

\author{
L. M. Stancanelli and E. Foti \\ University of Catania, Department of Civil Engineering and Architecture, Via Santa Sofia 64, 95123, Catania, Italy \\ Correspondence to: L. M. Stancanelli (lmstanca@dica.unict.it)
}

Received: 21 October 2014 - Published in Nat. Hazards Earth Syst. Sci. Discuss.: 20 November 2014

Revised: 12 February 2015 - Accepted: 11 March 2015 - Published: 7 April 2015

\begin{abstract}
A detailed comparison between the performances of two different approaches to debris flow modelling was carried out. In particular, the results of a mono-phase Bingham model (FLO-2D) and that of a two-phase model (TRENT2D) obtained from a blind test were compared. As a benchmark test the catastrophic event of 1 October 2009 which struck Sicily causing several fatalities and damage was chosen. The predicted temporal evolution of several parameters of the debris flow (such as flow depth and propagation velocity) was analysed in order to investigate the advantages and disadvantages of the two models in reproducing the global dynamics of the event. An analysis between the models' results with survey data have been carried out, not only for the determination of statistical indicators of prediction accuracy, but also for the application of the Receiver Operator Characteristic (ROC) approach. Provided that the proper rheological parameters and boundary conditions are assigned, both models seem capable of reproducing the inundation areas in a reasonably accurate way. However, the main differences in the application rely on the choice of such rheological parameters. Indeed, within the more user-friendly FLO-2D model the tuning of the parameters must be done empirically, with no evidence of the physics of the phenomena. On the other hand, for the TRENT-2D the parameters are physically based and can be estimated from the properties of the solid material, thus reproducing more reliable results. A second important difference between the two models is that in the first method the debris flow is treated as a homogeneous flow, in which the total mass is kept constant from its initiation in the upper part of the basin to the deposition in a debris fan. In contrast, the second approach is suited to reproduce the erosion and deposition processes and the displaced mass can be directly related to the rainfall event. Application of
\end{abstract}

both models in a highly urbanized area reveals the limitation of numerical simulation which is inadequate in describing some disturbances of the flows that occurred during the alluvial event (e.g. the cars, the volume of debris within buildings etc.) which have a crucial influence on the evaluation of the maximum and final flow depths.

\section{Introduction}

Debris flow occurrences are among natural phenomena which still produce damage and fatalities. Therefore in the last decades many efforts have been put in place to develop models able to simulate numerically the debris flow propagation, aiming at producing reliable hazard maps. It is possible to find several propagation models applicable to hyperconcentrated flows, which mainly differ for the adopted rheological schemes. In particular, they can be separated into singlephase models and two-phase models. Single-phase models assume that a debris flow acts as a homogeneous Bingham fluid composed of a mixture of water and sediment. From a rheological view point, such a mixture can be described by Herschel-Bulkley or even more complex models as, for example, that described by a quadratic law which assumes that the total friction stresses can be divided into different terms: yield stresses, viscosity stresses and turbulentdispersive stresses; all of them being functions of the sediment concentration in the mixture. In any case, the hypothesis of the Binghamian nature of the fluid is necessary in order to simulate the arrest of the flow.

When the debris flows are treated as a two-phase model, the exchange of mass between the erodible bed and the flow is taken into account as well. The fundamentals of such mod- 
els were first developed by Bagnold (1954) and then applied to the debris flows by Takahashi (1978). In such models the solid concentration is an unknown variable which influences the global behaviour of the flow that can be properly accounted for by the model itself.

In particular, it has been noticed that the first type of model is more suitable for cases characterized by fine sediments, when the viscous shear rate is high. The second type of model is more suitable in cases in which the viscosity of the interstitial fluid is negligible and the solid fraction is composed of coarser material, so that the inertial shear rate acts predominately due to the collisions between gravels.

Furthermore, as was stressed by Iverson et al. (1997) the debris flow during the propagation does not behave with a fixed rheology, since it changes its rheological characteristics in space and time.

In order to understand the real behaviour of the propagation of a debris flow on a large scale, a real catastrophic debris flow event was analysed by means of two different models: the FLO-2D (O'Brien, 1986) which is a single-phase model, and the TRENT-2D (Armanini et al., 2009) which is a two-phase model. Both models adopt depth-integrated flow equations, though they assume different mathematical descriptions of the phenomenon.

The FLO-2D model is a propagation code for analysing debris flow dynamics widely adopted by researchers and practitioners. Indeed, it is easy to find in the literature several applications of such a model, which mainly differ in relation to the sediment characteristics, and hence, in relation to the adopted rheological parameters (see, for example, Bertolo et al., 2005; Boniello et al., 2010; Wu et al., 2013). Various comparisons between its performances and those of other methodologies are also available. In particular, Armento et al. (2008) and Nocentini et al. (2014) compared the FLO-2D model with the DAN-W model, a onedimensional code based on a single-phase rheological approach. Both studies demonstrated that FLO-2D, if appropriately calibrated, represents a useful tool for predicting the behaviour of future landslides of the same type and in similar settings. The TRENT-2D model has been successfully applied in the eastern Italian Alps for studying the propagation of debris flows in erodible channels, with a significant entrainment of bed material during the propagation. The effectiveness of the code in developing hazard maps and in designing defence structures has been assessed by Armanini et al. (2009) and Rosatti et al. (2015). To our knowledge, there are no extensive published comparisons between TRENT-2D and other 2-D models.

In order to highlight the relative advantages and disadvantages of the two methodologies, they have been applied to a real complex case - namely, the alluvial event of 1 October 2009 which struck Messina Province (Italy) causing 37 fatalities and damage to public and private buildings and infrastructure. In particular, several debris flows in Giampilieri vil- lage, which was affected the most during the alluvial event, were simulated.

The paper is organized as follows: Sect. 2 presents a brief description of the two models; Sect. 3 describes the case study; Sect. 4 presents the boundary conditions along with data adopted as input for the two models; Sect. 5 reports the performed simulations; Sect. 6 shows the application of the ROC procedure to the case being. The paper ends with some conclusions about the main strengths and weaknesses of the two codes.

\section{Models description}

As mentioned before, the adopted models are based on depthintegrated flow equations, though they differ in the mathematical descriptions of the phenomenon. Indeed, the FLO2D model, which is not fully two-dimensional, is based on a monophasic Bingham scheme, modelled through the quadratic rheological law developed by O'Brien and Julien (1985). The TRENT-2D is a fully two-dimensional model and is a two-phase rheological model based on the dispersive shear stresses by Bagnold. Another important difference is that in the FLO-2D the concentration of the solid phase is kept constant along all the debris flow and for such condition the bed is fixed, while in the TRENT-2D the bed is mobile and completely coupled with the dynamic of the mixture. More in-depth model descriptions are provided in what follows.

\section{$2.1 \quad$ FLO-2D}

FLO-2D is a commercial code developed by O'Brien (1986) and adopted worldwide for debris flow phenomena modelling and delineating flood hazards. It is a pseudo 2-D model in space which adopts depth-integrated flow equations. Hyperconcentrated sediment flows are simulated considering the flow as a homogeneous (monophasic) non-linear Bingham fluid, based on an empirical quadratic rheological relation developed by O'Brien and Julien (1985). The basic equations implemented in the model consist mainly of the continuity equation

$$
\frac{\partial h}{\partial t}+\frac{\partial(h V)}{\partial x}=i
$$

and the equation of motion

$$
S_{\mathrm{f}}=S_{\mathrm{o}}-\frac{\partial h}{\partial x}-\frac{V}{g} \frac{\partial V}{\partial x}-\frac{1}{g} \frac{\partial V}{\partial t},
$$

where $h$ is flow depth, $V$ is depth-averaged velocity, $i$ is excess rainfall intensity (assumed equal to zero in the present application), $x$ is the generic direction of motion, $S_{\mathrm{f}}$ is the total friction slope, $S_{\mathrm{o}}$ is the bed slope, and $g$ is gravitational acceleration.

The surface topography is discretized into uniform square grid elements. In order to solve the momentum equation 
the FLO-2D considers, for each cell, eight potential flow directions. Each velocity computation is essentially onedimensional and solved independently from the other seven directions, so $h$ and $V$ are related to one of the eight flow directions $x$.

The total friction slope $S_{\mathrm{f}}$ can be expressed as follows:

$S_{\mathrm{f}}=\frac{\tau_{\mathrm{B}}}{\rho g h}+\frac{K \mu_{\mathrm{B}} V}{8 \rho g h^{2}}+\frac{n^{2} V^{2}}{h^{\frac{4}{3}}}$,

where $\tau_{\mathrm{B}}$ is Bingham yield stress, $\rho$ is mixture density, $K$ is the laminar flow resistance coefficient, $\mu_{\mathrm{B}}$ is Bingham viscosity, and $n$ is the pseudo-Manning resistance coefficient which accounts for both turbulent boundary friction and internal collisional stresses. In particular, the yield stress $\tau_{\mathrm{B}}$, the dynamic viscosity $\mu_{\mathrm{B}}$ and the resistance coefficient $n$ are influenced by the sediment concentration relationships and, therefore, can be described by the following equations (O’Brien, 2007):

$\tau_{\mathrm{B}}=\alpha_{1} e^{\beta_{1} C_{\mathrm{v}}}$

$\mu_{\mathrm{B}}=\alpha_{2} e^{\beta_{2} C_{\mathrm{v}}}$

$n=n_{\mathrm{t}} 0.538 e^{6.0896 C_{\mathrm{v}}}$,

where $C_{\mathrm{v}}$ is the volumetric concentration and $\alpha_{1}, \beta_{1}, \alpha_{2}$ and $\beta_{2}$ are empirical coefficients defined by laboratory experiments by O'Brien and Julien (1988) and $n_{\mathrm{t}}$ is the turbulent $n$ value by Julien and O'Brien (1998). More detailed information about the numerical scheme and the general constitutive fluid equations adopted can be found in O'Brien (2007).

\subsection{TRENT-2D}

TRENT-2D is a code developed by Armanini et al. (2009) for the simulation of hyperconcentrated sediment transport and debris flows. It is based on a two-phase approach, in which the interstitial fluid is water and the granular phase is modelled according to the dispersive pressure theory of Bagnold (1954), applied to the debris flows according to the adaptations introduced by Takahashi (1978). Since the reference model is biphasic, the concentration is one of the unknowns of the model and the bed is movable. Moreover, the dynamics of the mixture and the morphological evolution of the bed are solved in a completely coupled way. This is quite important because wave celerities change noticeably from the fixed to the movable bed case. The model is based on the balance equations for mass and momentum (related to solid and mix- ture):

$\left\{\begin{array}{c}\frac{\partial\left(z_{B}+h\right)}{\partial t}+\frac{\partial\left(h V_{x}\right)}{\partial x}+\frac{\partial\left(h V_{y}\right)}{\partial y}=0 \\ \frac{\partial\left(c_{B} z_{B}+c h\right)}{\partial t}+\frac{\partial\left(c h V_{x}\right)}{\partial x}+\frac{\partial\left(c h V_{y}\right)}{\partial y}=0 \\ \frac{\partial\left(c_{\Delta} V_{x} h\right)}{\partial t}+\frac{\partial\left[c_{\Delta}\left(V_{x}^{2} h+\frac{g h^{2}}{2}\right)\right]}{\partial x}+\frac{\partial\left(c_{\Delta} V_{x} V_{y} h\right)}{\partial y}+c_{\Delta} g h \frac{\partial z_{B}}{\partial x} \\ =-F_{V_{x}} \\ \frac{\partial\left(c_{\Delta} V_{y} h\right)}{\partial t}+\frac{\partial\left(c_{\Delta} V_{x} V_{y} h\right)}{\partial x}+\frac{\partial\left[c_{\Delta}\left(V_{y}^{2} h+\frac{g h^{2}}{2}\right)\right]}{\partial y}+c_{\Delta} g h \frac{\partial z_{B}}{\partial y} \\ =-F_{V_{y}},\end{array}\right.$

where $x$ and $y$ are the two directions of motion, $V_{x}$ and $V_{y}$ are depth-averaged velocity components along the $x$ and $y$ coordinates, $z_{\mathrm{B}}$ is bed elevation, $c$ is solid phase concentration, $c_{\mathrm{b}}$ is solid concentration into the soil, and $c_{\Delta}=(1+\Delta c)$ where $\Delta=\left(\rho_{\mathrm{s}}-\rho_{\mathrm{w}}\right) / \rho_{\mathrm{w}}$ is relative submerged density of solid phase $\left(\rho_{\mathrm{w}}\right.$ and $\rho_{\mathrm{S}}$ are the densities of the water and of the solid respectively), and $F_{V_{x}}$ and $F_{V_{y}}$ are friction term components along the $x$ and $y$ coordinates. The friction term $F=F(|v|, h)$ derives from the Bagnold relation, modified by Takahashi (1978) on the basis of experimental data:

$F=25 / 4(1+\Delta) \sin \varphi \lambda^{2} Y^{2}$

where $\varphi$ is the friction angle and

$\lambda=\left[\left(c_{b} / c\right)^{1 / 3}-1\right]^{-1} ; Y=h /\left(d_{50} \sqrt{a}\right)$,

where $d_{50}$ is the median grain size and $a=0.32$ is a constant determined in laboratory setting by Takahashi (1978). The concentration is computed as a function of the flow variables as

$c=\beta c_{b}\left(V^{2} / g h\right)$,

where the transport capacity $\beta$ is a dimensionless parameter. The numerical scheme, second-order accurate both in space and in time, is based on a finite volume, Godunov approach over a Cartesian structured grid. The scheme follows a MUSCL-Hancock explicit time stepping approach. The numerical fluxes at cell interfaces are computed using the LHLL Riemann solver as in Fraccarollo et al. (2003), which is able to account for the non-conservative terms due to bed discontinuities. More details on the mathematical scheme and on the numerical model can be found on the TRENT-2D User's Manual (2011).

\section{Case study description}

During the night of 1 October 2009 a heavy rainfall struck the Province of Messina causing 37 fatalities and several damage to public and private structures. This area located along the coast is characterized by the presence of the Peloritan Arc, which determines a particular morphology characterized by 
narrow river valleys with high hillslope angles (within a range of $30-60^{\circ}$ ) and with catchment basins of small or moderate extensions (within a range of $0.5-12 \mathrm{~km}^{2}$; Fig. 1). The soil is composed of metamorphic material, easily eroded, due in part to the semi-arid climate, which is characterized by short and very intense rainstorms that occur between October and March. The event occurred in an area of more than $50 \mathrm{~km}^{2}$, generating over 600 landslides in a few hours. One of the most damaged villages was Giampilieri, a small village in the Southern Messina Province, located on the left bank of the Giampilieri river. The town is characterized by a high-density urban area with narrow streets, that become, during alluvial events, the bed over which the runoff flows. Upstream of the Giampilieri urbanized area, there are three different tributaries named, from west to east, Loco, Sopra Urno and Puntale creeks respectively (Fig. 2a). All these tributaries are characterized by catchments of small extension of $0.15 \mathrm{~km}^{2}$ for the Loco Basin, $0.07 \mathrm{~km}^{2}$ for the Sopra Urno Basin and $0.04 \mathrm{~km}^{2}$ for the Puntale Basin. During the alluvial event of 1 October 2009, all the three catchments produced debris flows that hit the village and caused 19 fatalities. The overall effect of the rainfall event on the slopeland surface is easy to ascertain thanks to a simple comparison between orthophotos gathered respectively before and after the alluvial event (Fig. 2b and c respectively); at a glance it is possible to have an idea of the huge debris flow magnitude involved.

\section{Input data for modelling}

In order to model the debris flows, three principal data sets are needed: a digital terrain model (DTM), hydrological data, and rheological properties of the sediment-water mixture. While the first two data sets are the same for the two models, the rheological properties are very different. The geometry inputs consist in the definition of a flood plain area. LIDAR data characterized by a spatial resolution of eight points per square metre were adopted for the construction of the DTM. Moreover, for the urbanized area further elevation data were acquired on purpose through a theodolite. The different grid systems implemented by FLO-2D model and by TRENT-2D model were designed in such a way that a grid of square cells with cell size $1.5 \mathrm{~m} \times 1.5 \mathrm{~m}$ was adopted for both models. In order to simplify the comparison between the different outputs a coordinate system was set equal for the two different simulations. The presence of buildings inside the flood plain was considered in both models, thus obtaining the same final configuration, although the implementation of such a feature is performed in FLO-2D and TRENT-2D in different ways. Indeed, the FLO-2D model is able to consider such a feature, attributing a reduction factor that accounts for the loss of storage and redirection of the flow path, while within the TRENT-2D the presence of buildings is implemented by enhancing the elevation of the cell where the contour layer of buildings itself. In the case being for both models the cells where the buildings are located have been considered not able to be inundated and thus to store debris flow volume.

Regarding the hydrological input, the hydrological inputs relative to the three mentioned data sets were considered. The same input hydrograph was used for both FLO-2D and TRENT-2D simulations; the rate of water discharge corresponds to a rainfall of a 300-year return period. The time evolution of the hydrograph is assumed to have a triangular distribution with a base time equal to the concentration time of each basin (Fig. 3). This hydrograph is applied at the upstream section of the basin, where the triggering was observed. In order to determine the discharge rate value of the debris flows for each basin, the formula derived by Armanini et al. (2009) has been used:

$Q_{\mathrm{df}}=Q_{1} \frac{c_{\mathrm{b}}}{c_{\mathrm{b}}-c}$,

where $Q_{\mathrm{df}}$ is the discharge of debris flow, $Q_{1}$ is the liquid discharge rate (given by the hydrograph), and $c$ and $c_{\mathrm{b}}$, as already described, are the concentration of the solid phase in the debris flow and into the soil, respectively. The debris flow concentration is calculated according to the following expressions:

$$
\begin{array}{lll}
c=\frac{1}{\Delta} \frac{\tan \alpha}{\tan \varphi-\tan \alpha} & \text { for } & \alpha \leq 21^{\circ} \\
c=0.9 c_{b} & \text { for } & \alpha \geq 21^{\circ},
\end{array}
$$

where $\alpha$ if the slope angle in the upstream section of the model. The above relationships are consistent with the rheological assumptions of the TRENT-2D model. From the above equations it is possible to argue that $c$ cannot exceed $0.9 c_{\mathrm{b}}$, when the bed slope is higher than a fixed threshold (which in this case is equal to $21^{\circ}$ ) and that the slope $\alpha$ cannot exceed the friction angle $\varphi$.

It should be noted that in general the upstream input discharge $Q_{\text {df }}$ is rather sensitive to the value of the bed slope $\alpha$, but the value of upstream input discharge has minor influence on the downstream features of the debris flows in the TRENT-2D model, because of its capability to reproduce the erosion and deposition processes that along the flow are able to change the local discharge according to the local geometry. In contrast, this is not possible with the FLO-2D model, in which the discharge, instead, can be changed only by modifying the excess rainfall intensity - otherwise it remains constant along its entire course. Nevertheless we have used Eq. (11) also to assign the input discharge in the simulation with FLO-2D.

The debris flow discharge was determined by applying equation (11) in the upper part of the basin, where the triggering of the phenomenon was observed. Areas characterized by a slope in the range of $30^{\circ}-60^{\circ}$ (higher than the threshold value $21^{\circ}$ provided by Eq. 12) generate a debris flow discharge that is about 10 times larger than the triggering water discharge. However, this assumption induces in the FLO-2D model an error in the volumes, because Eq. (11) also includes 


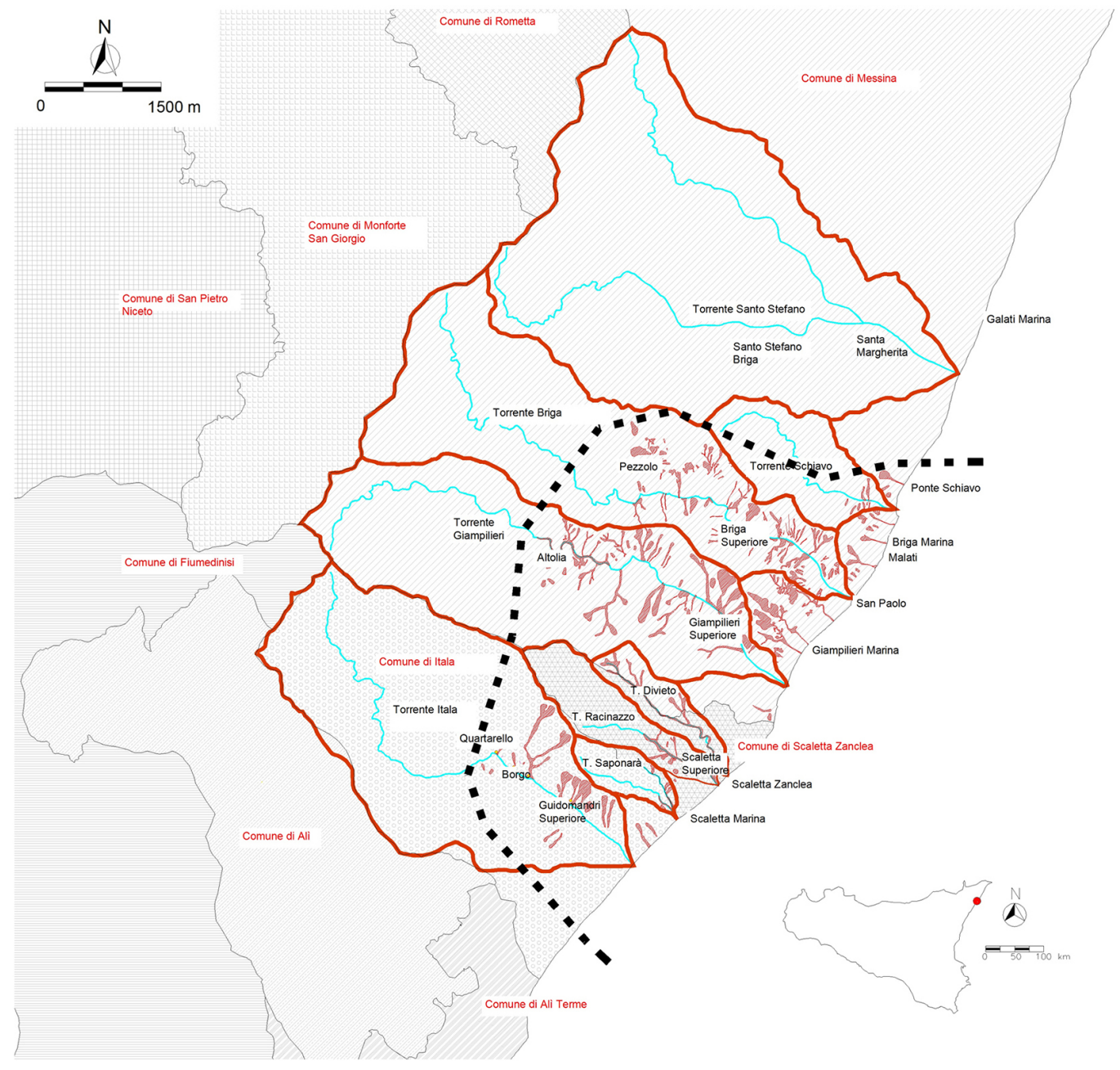

Figure 1. Map of Northeast Sicily struck by the debris flow on 1 October 2009.

the liquid discharge, that, reasonably, contributes only partly to deposited volumes.

While for the Puntale and Loco creeks only one hydrological input was considered, for the Sopra Urno Basin three inputs were implemented. Such an assumption relies on the observed event dynamics and from the analysis of the orthophoto gathered just after the event, in which it is easy to distinguish the three sub-catchments. Also, it was assumed that the debris flows that originated from the three subcatchments did not develop at the same time, but were separated from each other by $6 \mathrm{~min}$. This is supported by videos of the event as well as by a comparison between the volumes calculated from the hydrographs and those resulting from the surveys taken after the event.

Regarding the rheological parameters, the FLO-2D model relies on empirical parameters, while the TRENT-2D parameters have a more specific physical meaning.

The mono-phase modelling approach suffers from a need for calibration with historical data, while a more physically based model, such as the adopted two-phase one, is easier to apply. Indeed in order to perform the simulations with the FLO-2D model, the coefficients $\alpha_{1}, \beta_{1}, \alpha_{2}$ and $\beta_{2}$ (Eqs. 4 and $5)$ need to be estimated. Due to the mono-phase rheology the model is based upon, the parameters cannot be directly evaluated, and must be estimated. Here the following values were assumed: $\alpha_{1}=0.006032 ; \beta_{1}=19.9 ; \alpha_{2}=0.000707$; $\beta_{2}=29.8$. These values were chosen from the ones available in the literature, with the aim of selecting those that have similar geomorphological and lithological characteristics to those present in the studied area (O'Brien and Julien, 1988; Bertolo et al., 2005; Boniello et al., 2010; Wu et al., 2013). In order to perform the simulations with the TRENT-2D model, it is necessary to estimate the parameters $\varphi, Y$ and $\beta$ (Eqs. 810). The rheological data to be used in TRENT-2D (such as friction angle, transport capacity, etc.) were chosen from values usually adopted in the literature for soil characteristics similar to those of the Messina region. Although the friction angle $\varphi$ can be determined by laboratory tests on the soil ma- 

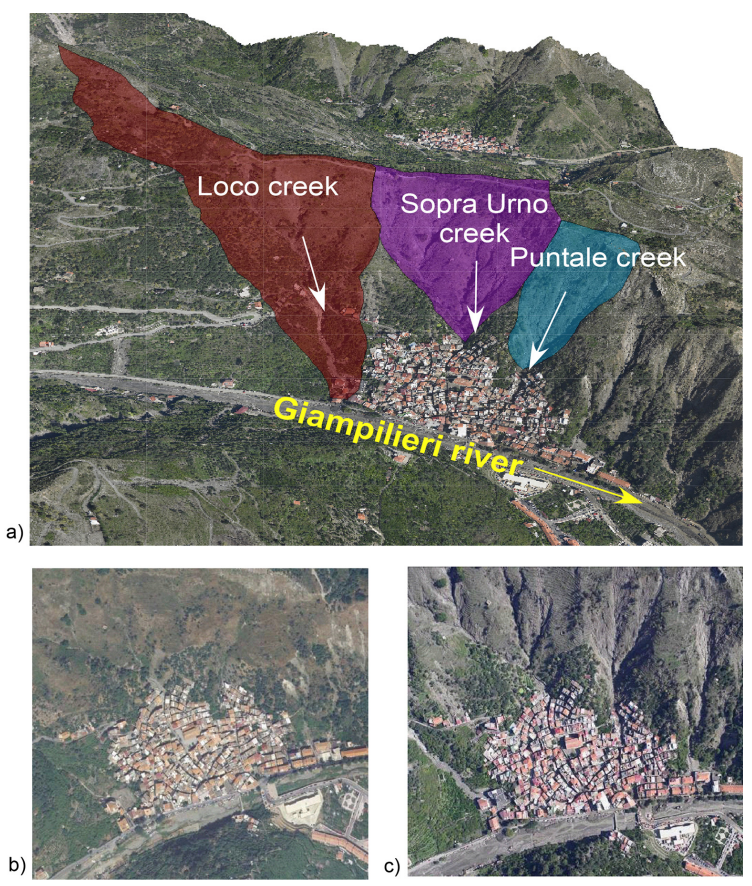

Figure 2. Orthophoto of Giampilieri village: (a) the locations of Loco, Sopra Urno and Puntale creeks and Giampilieri River are indicated; (b) the village prior to the alluvial event; (c) the village after the alluvial event.

Table 1. Input data of the hydrograph and rheology adopted for FLO-2D and TRENT-2D simulations. For the FLO-2D: solid concentration in the mixture $c$, and the rheological coefficients $\alpha_{1}, \beta_{1}$, $\alpha_{2}$ and $\beta_{2}$; for the TRENT-2D: the solid concentration into the soil $c_{\mathrm{b}}$, relative submerged density of solid phase $\Delta$, friction angle $\varphi$, submergence $Y$ and transport capacity $\beta$.

\begin{tabular}{ccccc|ccccc}
\hline \multicolumn{7}{c}{ FLO-2D } & \multicolumn{5}{c}{ TRENT-2D } \\
$c$ & $\alpha_{1}$ & $\beta_{1}$ & $\alpha_{2}$ & $\beta_{2}$ & $c_{\mathrm{b}}$ & $\Delta$ & $\varphi$ & $Y$ & $\beta$ \\
\hline 0.5 & 0.006032 & 19.9 & 0.000707 & 29.8 & 0.65 & 1.6 & $38^{\circ}$ & 10 & 6 \\
\hline
\end{tabular}

terial of the study site, here it was assumed as $\varphi=38^{\circ}$. The parameter $Y$ was set equal to 10 , considered an average value of its expression throughout the flow field (Eq. 9). Finally, the transport capacity $\beta$ was determined as explained in the TRENT-2D User's Manual (2011), and therefore $\beta=6$ was assumed.

Table 1 reports and summarizes all input parameters, useful for the hydrograph definition and rheologies description, implemented for the FLO-2D and TRENT-2D simulations.

\section{Performed simulations}

Regarding the simulation performed by the FLO-2D, a reconstruction of the inundated area was obtained as output of the model. It is easy to recognize the portion of the urbanized area affected by the debris flow, which fits fairly well

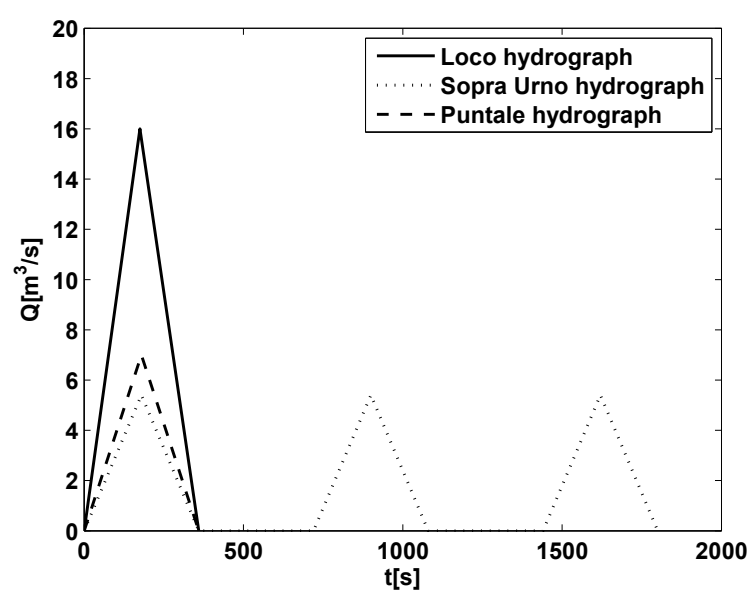

Figure 3. Input liquid hydrographs assumed for triggering debris flows in FLO-2D and TRENT-2D simulations for Loco Basin, Sopra Urno Basin and Puntale Basin.

with the surveys conducted just after the event. The maximum flow depths during the event obtained from the FLO2D simulation are presented in Fig. 4a. The highest predicted flow depths were generated by the Sopra Urno Creek, with a maximum value of about $6 \mathrm{~m}$. Figure $4 \mathrm{~b}$ represents the final flow depths, i.e. the debris flow depths after a time of $3 \mathrm{~h}$. Note that, according to the mono-phase approach, there are no bed variations nor settlement of sediments separated from the liquid phase. The whole fluid stops when the bed stress goes under a threshold that depends on the fluid, thus determining the final deposition. The highest values of the predicted final flow depths are found in the streets perpendicular to the main path followed by the debris flows, with a maximum value of $1.2 \mathrm{~m}$. Finally, the predicted maximum velocities are shown in Fig. 4c. It is easy to recognize that the maximum velocities are registered in correspondence of the upper part of the basins, where the slope is the highest, with values ranging from 10 to $20 \mathrm{~m} \mathrm{~s}^{-1}$, while inside the urbanized area the velocities range from 1.5 to $5 \mathrm{~m} \mathrm{~s}^{-1}$, although some peaks over $10 \mathrm{~m} \mathrm{~s}^{-1}$ are also observed.

As regards the simulation performed by TRENT-2D, the maximum flow depths reached during the simulations of the event are shown in Fig. 5a. The values are generally smaller than those predicted by the FLO-2D model for the same case. On the other side, considering the thickness of the final deposition of material (Fig. 5b), the TRENT-2D predicted values are greater than those provided by the FLO-2D, in particular along the main path followed by the debris flows. Finally, the maximum velocities given by the TRENT-2D model are shown in Fig. 5c. They are generally smaller than those obtained using the FLO-2D, with velocities around $1-1.5 \mathrm{~m} \mathrm{~s}^{-1}$ along the main paths and smaller values elsewhere.

The results of both FLO-2D and TRENT-2D were compared with the data gathered from on-site investigations, i.e. videos recorded during the event and measurements of the 
Table 2. Measured and predicted values of maximum flow depth $\left(h_{\max }\right)$ and of thickness of final sediments deposition $\left(h_{\text {final }}\right)$ for the Giampilieri event. Maximum velocities $\left(v_{\max }\right)$ are available as output of model simulations.

\begin{tabular}{|c|c|c|c|c|c|c|c|c|}
\hline \multirow{2}{*}{$\begin{array}{l}\text { POS. } \\
\text { (no.) }\end{array}$} & \multicolumn{2}{|c|}{ Survey data } & \multicolumn{3}{|c|}{ FLO-2D } & \multicolumn{3}{|c|}{ TRENT-2D } \\
\hline & $\begin{array}{r}h_{\max } \\
(\mathrm{m})\end{array}$ & $\begin{array}{r}h_{\text {final }} \\
(\mathrm{m})\end{array}$ & $\begin{array}{r}h_{\max } \\
(\mathrm{m})\end{array}$ & $\begin{array}{r}h_{\text {final }} \\
(\mathrm{m})\end{array}$ & $\begin{array}{r}v_{\max } \\
\left(\mathrm{m} \mathrm{s}^{-1}\right)\end{array}$ & $\begin{array}{r}h_{\max } \\
(\mathrm{m})\end{array}$ & $\begin{array}{r}h_{\text {final }} \\
(\mathrm{m})\end{array}$ & $\begin{array}{r}v_{\max } \\
\left(\mathrm{m} \mathrm{s}^{-1}\right)\end{array}$ \\
\hline 1 & 2.4 & 2.0 & 1.4 & 0.4 & 2.7 & 1.2 & 1.1 & 0.6 \\
\hline 2 & 1.8 & 1.0 & 2.7 & 0.8 & 1.5 & 1.4 & 1.2 & 0.7 \\
\hline 3 & 1.5 & 0.8 & 3.9 & 0.9 & 2.0 & 0.8 & 0.6 & 0.5 \\
\hline 4 & 1.7 & 1.0 & 4.4 & 1.1 & 4.1 & 0.8 & 0.5 & 0.4 \\
\hline 5 & 2.0 & 1.5 & 4.5 & 1.1 & 4.1 & 0.9 & 0.5 & 0.6 \\
\hline 6 & 3.3 & 2.0 & 4.5 & 1.1 & 3.5 & 1.1 & 0.5 & 0.6 \\
\hline 7 & 3.0 & 0.0 & 4.0 & 0.5 & 3.8 & 1.4 & 0.6 & 0.8 \\
\hline 8 & 2.2 & 0.0 & 4.8 & 0.2 & 6.3 & 1.4 & 0.7 & 0.9 \\
\hline 9 & 3.3 & 0.0 & 1.5 & 0.3 & 3.6 & 1.4 & 0.8 & 0.6 \\
\hline 10 & 1.3 & 0.0 & 1.2 & 0.3 & 5.0 & 1.1 & 0.6 & 0.3 \\
\hline 11 & 2.8 & 2.0 & 1.8 & 0.1 & 2.0 & 1.7 & 0.3 & 1.0 \\
\hline 12 & 1.7 & 0.0 & 0.1 & 0.0 & 0.1 & 1.4 & 0.7 & 0.4 \\
\hline 13 & 2.1 & 1.0 & 2.0 & 0.7 & 1.7 & 2.2 & 1.4 & 1.1 \\
\hline 14 & 2.0 & 0.0 & 0.2 & 0.0 & 2.0 & 2.1 & 1.8 & 0.3 \\
\hline 15 & 1.3 & 1.0 & 2.5 & 0.2 & 3.5 & 1.4 & 1.0 & 0.4 \\
\hline 16 & 2.6 & 0.0 & 3.1 & 0.1 & 5.0 & 2.7 & 1.1 & 1.3 \\
\hline 17 & 2.1 & 0.0 & 4.7 & 0.5 & 5.0 & 2.3 & 1.3 & 0.9 \\
\hline 18 & 0.9 & 0.0 & 2.3 & 0.1 & 2.8 & 1.2 & 0.3 & 0.3 \\
\hline 19 & 2.4 & 1.5 & 0.4 & 0.1 & 3.5 & 0.4 & 0.2 & 0.4 \\
\hline 20 & 2.2 & 0.0 & 1.6 & 0.4 & 0.6 & 1.8 & 0.1 & 0.3 \\
\hline 21 & 2.4 & 0.0 & 0.0 & 0.0 & 0.4 & 2.0 & 0.3 & 0.2 \\
\hline 22 & 2.9 & 0.0 & 0.1 & 0.1 & 0.1 & 0.7 & 0.1 & 0.7 \\
\hline 23 & 2.0 & 1.0 & 2.3 & 0.5 & 0.8 & 1.2 & 0.4 & 0.7 \\
\hline 24 & 2.8 & 0.5 & 2.1 & 0.4 & 0.8 & 0.7 & 0.3 & 0.4 \\
\hline 25 & 2.3 & 1.5 & 2.2 & 0.4 & 0.7 & 1.2 & 0.6 & 0.5 \\
\hline 26 & 1.9 & 1.8 & 2.1 & 0.1 & 5.0 & 2.7 & 0.6 & 0.7 \\
\hline 27 & 2.0 & 1.5 & 4.0 & 1.0 & 1.9 & 2.1 & 1.0 & 0.4 \\
\hline 28 & 5.0 & 0.5 & 2.8 & 0.1 & 1.3 & 1.4 & 0.3 & 0.1 \\
\hline 29 & 5.0 & 0.0 & 4.5 & 0.5 & 8.0 & 5.5 & 0.7 & 1.4 \\
\hline 30 & 2.0 & 0.5 & 1.7 & 0.7 & 3.0 & 2.3 & 0.3 & 0.3 \\
\hline 31 & 1.5 & 1.5 & 0.0 & 0.0 & 0.3 & 0.3 & 0.1 & 0.2 \\
\hline
\end{tabular}

depth of the sediment deposition gathered just after the event. For example in Fig. 6 is presented a picture gathered after the alluvial event from which it is possible to individuate the maximum depth occurred in a particular section during the event. The latter data belong to the depositional map made after the alluvial event, where the levels of sedimentation material along the streets of Giampilieri village are indicated (see the Supplement). Figure 7 shows an orthophoto of the urban area of Giampilieri with the measurement positions used for the present study.

In particular, two field data sets are available: the values of the maximum flow depth reached during the event $\left(h_{\max }\right)$ and the values of the thickness of the sediment deposit left by the debris flow $\left(h_{\text {final }}\right)$. In Table 2 , field data are reported, along with the corresponding predicted data obtained from FLO2D and TRENT-2D - we report only the points for which both flow depth and deposit data are available.
Regarding maximum flow depths $\left(h_{\max }\right)$, FLO-2D predicted values are, in general, higher than those observed. This can be explained by considering that buildings cannot store debris flow volume and the uncertainty relative of the magnitude event. On the other hand, TRENT-2D results are slightly smaller than those observed, with more accurate results along the main paths and greater deviations in the smallest streets.

Predicted values obtained from FLO-2D simulations are smaller than survey data, perhaps due to the value of the viscosity parameter assumed and also the absence of anthropic features in the simulated scenario, such as cars along the streets, which during the event influenced the flow to a large extent. Looking at the TRENT-2D results, predicted final depositions are smaller than those measured. As for the flow heights, results are better in the main streets and less accurate in the lateral narrow ones. TRENT-2D is a movable bed model and, hence, allows the erosion caused by the debris 
a)

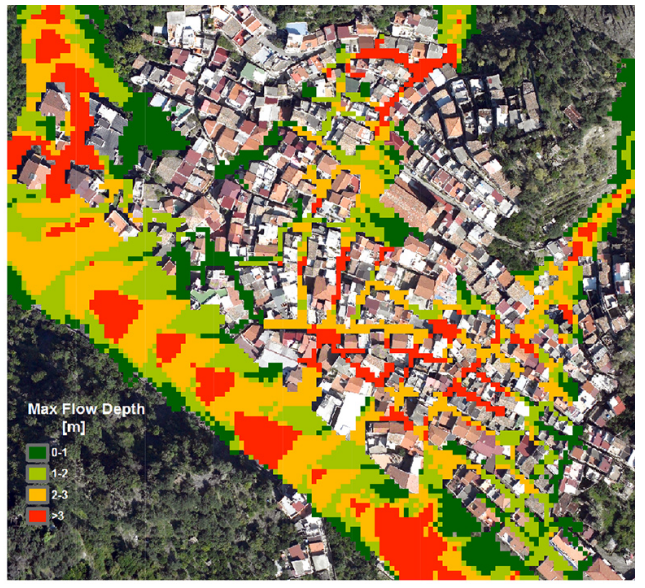

b)

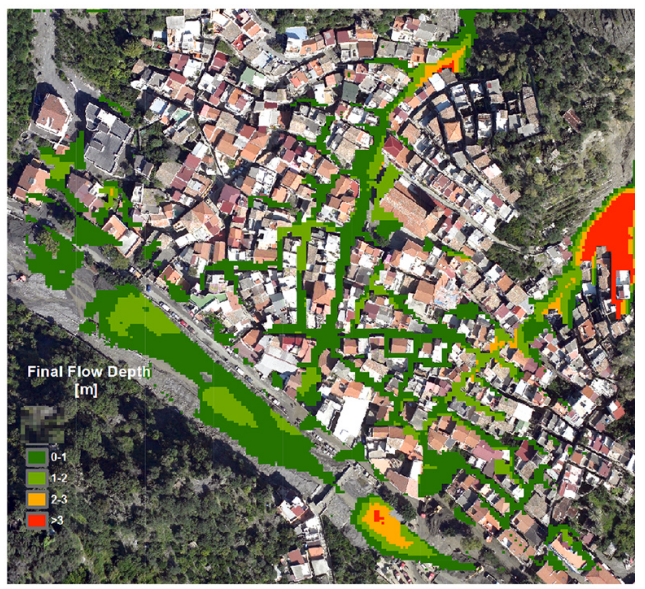

c)

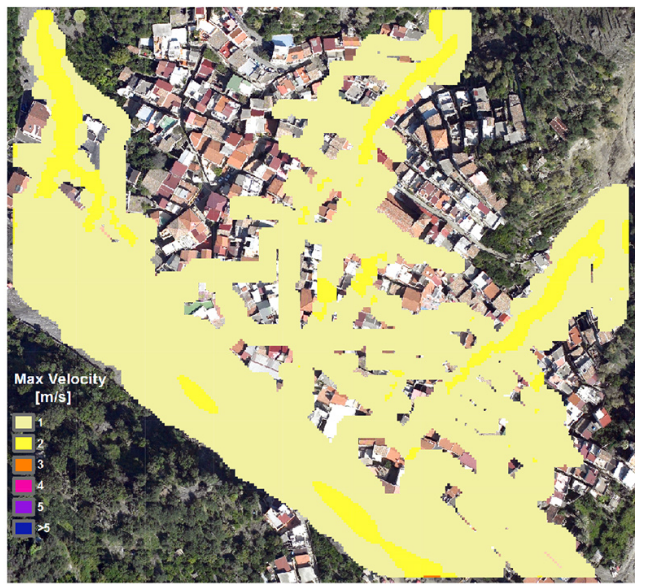

Figure 4. Scenarios simulated with the FLO-2D (hydraulic discharge relative to 300 -year return period; rheological parameters: $\alpha_{1}=0.006032 ; \beta_{1}=19.9 ; \alpha_{2}=0.000707 ; \beta_{2}=29.8$ ): (a) maximum flow depth; (b) final flow depth; (c) maximum velocities. a)

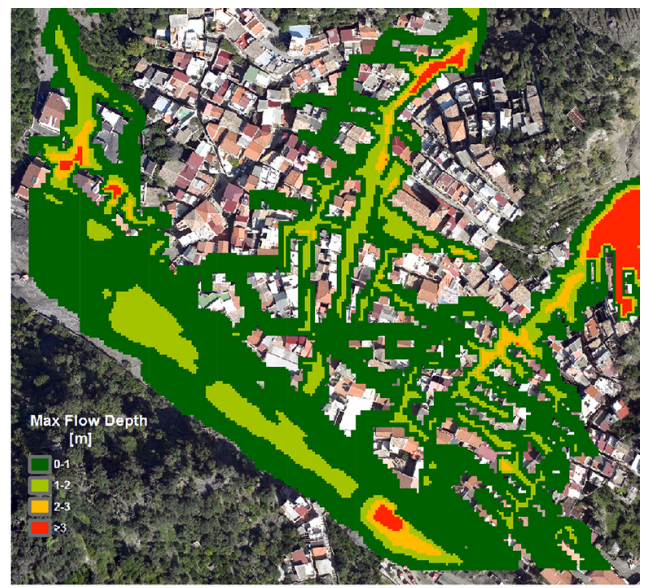

b)

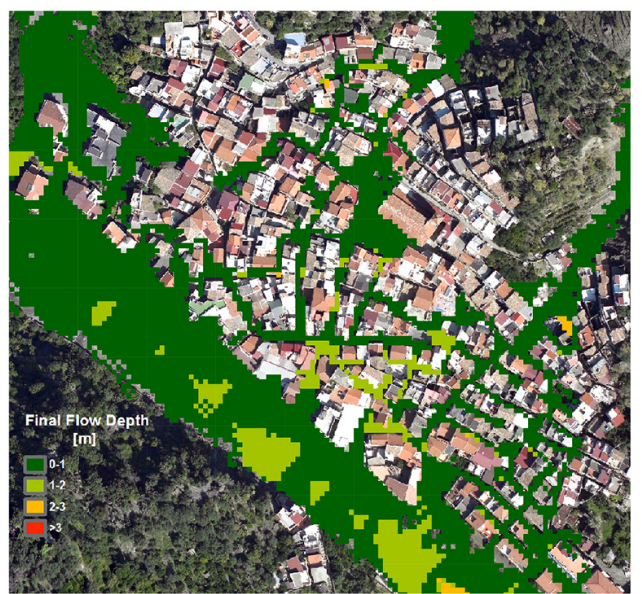

c)

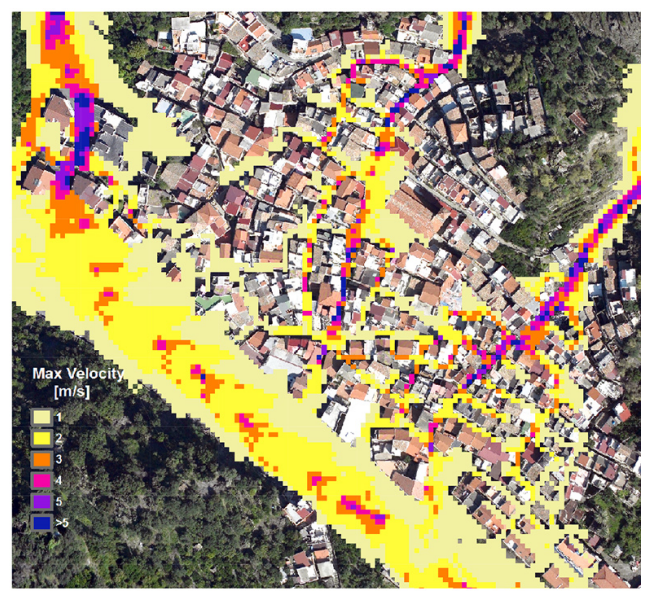

Figure 5. Scenarios simulated with the TRENT-2D (hydraulic discharge relative to 300-year return period; rheological parameters: $\varphi=38^{\circ} ; Y=10 ; \beta=6$ ): (a) maximum flow depth; (b) depth of the final sediment deposition; (c) maximum velocities. 


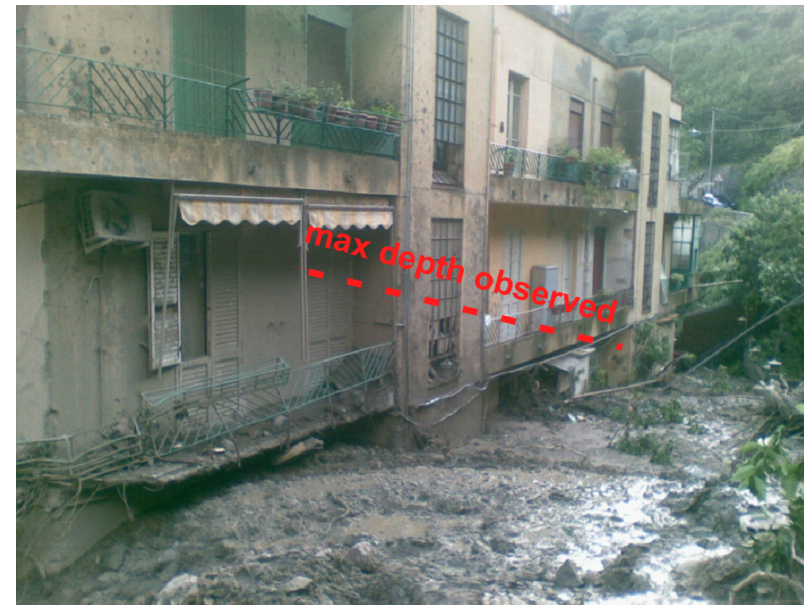

Figure 6. Evidence on the wall of the maximum depth observed during the event.

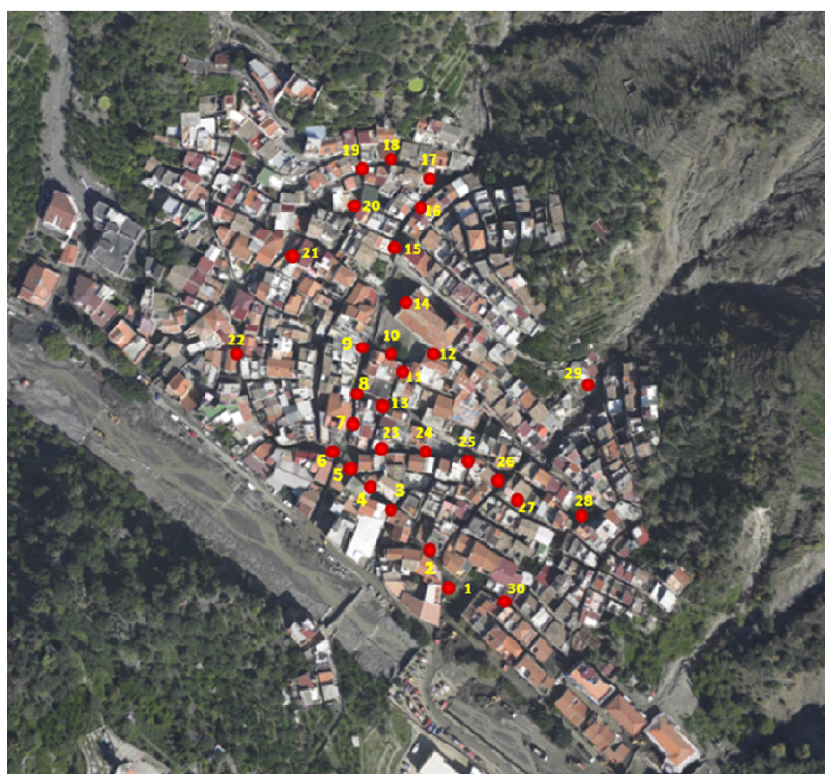

Figure 7. Orthophoto of Giampilieri urban area with positions where data of maximum flow depths and final sediment deposits are available from site surveys.

flow propagation to be estimated. For the present case study, the maximum scour caused by bed erosion was about $2-3 \mathrm{~m}$. This estimate is in accordance with the scour data collected after the debris flow event (see Fig. 2c).

Considering the maximum velocities $\left(v_{\max }\right)$, there are no field data available. Using FLO-2D, all values belong to the range from 1.5 to $20 \mathrm{~m} \mathrm{~s}^{-1}$, while using TRENT-2D velocities are much smaller (1-2 $\mathrm{m} \mathrm{s}^{-1}$ along the main paths and smaller values elsewhere). Such a difference is clearly due to the different rheologies adopted by the two models.

Although no field measures of debris flow velocities are directly available for the event here considered, the applica- tion of the formula proposed by Julien and Paris (2010):

$v_{m}=5.75 \sqrt{g h S} \log \frac{h}{d_{50}}$

suggests that debris flow velocities along the main propagation path can vary within a range of $4-30 \mathrm{~m} \mathrm{~s}^{-1}$. Here, $S$ is the friction slope, $d_{50}$ is the median grain diameter, and $h$ the debris flow depth, ranging from 1 to $3 \mathrm{~m}$ along the main path. On the other hand, field observations along the Moscardo River basin (Arattano et al., 2005; Marchi et al., 2002), characterized by a slope and a sediment material similar to that considered here, indicate a velocity ranging of 0.9 to $4 \mathrm{~m} \mathrm{~s}^{-1}$. Therefore, according to the results of the present simulations, TRENT-2D tends to underestimate the debris flow velocities, while FLO-2D seems to provide velocity estimates more similar to that experienced in the field.

In order to have a clearer view of the error distribution inside the flooded area, Fig. 8a and b indicate at each surveyed point (see Fig. 7) with dots of different colour the range of error in evaluating the maximum surface elevation, respectively for FLO-2D and TRENT-2D, considering a threshold of $30 \%$ of error. In such a case it is possible to individuate the FLO-2D simulation overestimate for the upper part of the basin, while the TRENT-2D is more accurate in the upper part and underestimates for more distant locations.

Finally, some statistical analysis on the models performances have been conducted. The mean absolute error and the root mean square error have been determined for each model, as 1.2 and 1.5 respectively for the FLO-2D and 0.9 and 1.2 for the TRENT-2D.

\section{Comparison of the models' performances, application of the ROC approach}

In order to compare, not only by means of simple statistical indicators, the results obtained by the two debris flow models, the Receiver Operator Characteristic (ROC) approach was applied. Such a method was originally developed to assess the performance of models in signal detection theory and then applied in different fields such as epidemiology, weather forecasting, machine learning and landslide susceptibility (Baum et al., 2010).

In a ROC graph the true positive rate (Sensitivity) is plotted vs. the false positive rate (Specificity) for a cut-off point. The sensitivity and the specificity are determined as follows:

Sensitivity $=\frac{\mathrm{TP}}{\mathrm{TP}+\mathrm{FN}} ; \quad$ Specificity $=\frac{\mathrm{FP}}{\mathrm{FP}+\mathrm{TN}}$.

In the literature it is possible to find several application of ROC in cases of regional landslide susceptibility models that rely on limit equilibrium calculations to evaluate the slope stability. In such a framework, the application of ROC is based on two states (stable and unstable) and on the basis of a grid analysis at each cell to which is assigned just one 

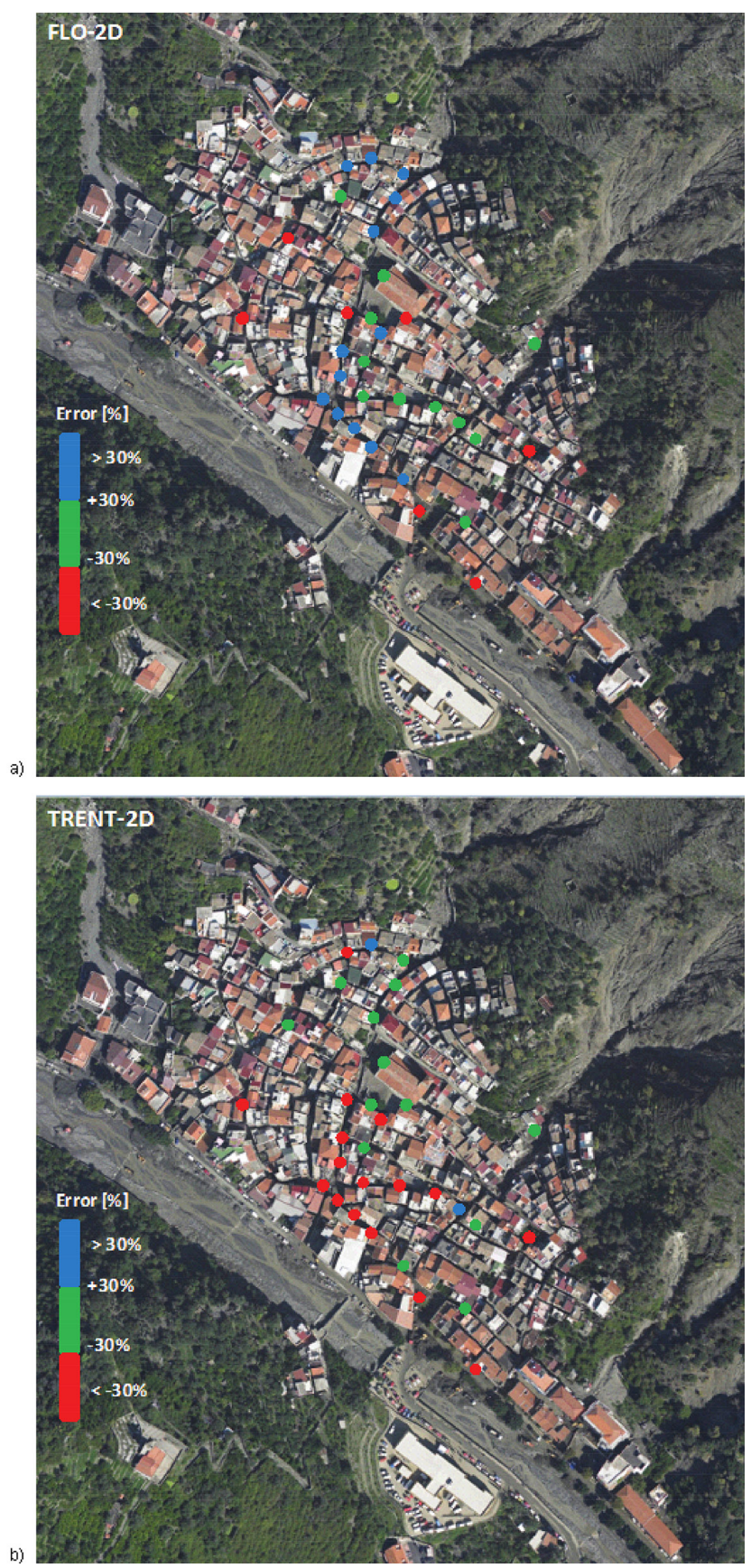

Figure 8. Giampilieri village map indicating with coloured dots the prediction error [\%] for (a) FLO-2D and (b) TRENT-2D.

of the four outcomes possible (true positive TP, false positive FP, false negative FN, true negative TN).

A point in the ROC graph represents a sensitivity/specificity pair corresponding to a particular decision threshold. A test with perfect discrimination is located in the ROC graph in the upper left corner $(100 \%$ sensitivity, $0 \%$ specificity). Therefore the closer a test is located in the ROC graph near the upper left corner, the higher the overall accuracy of the test (Zweig and Campbell, 1993).

In this framework the ROC approach was applied in order to evaluate the prediction of the two debris flow propagation models. The ROC graph was determined for a cut-off value of $1.0 \mathrm{~m}$ of $h_{\max }$ flow depth. In particular the two states for the ROC approach are: cell with max flow depth $\geq 1.0 \mathrm{~m}$ and cell with max flow depth $<1.0 \mathrm{~m}$, so the four outcomes are: (i) if the cell in the simulation is affected by the maximum debris flow depth $\geq 1.0 \mathrm{~m}$ and during the event a maximum flow depth $\geq 1.0 \mathrm{~m}$ has been observed, then the outcome is true positive TP; (ii) if during the event a maximum flow depth $<1.0 \mathrm{~m}$ has been observed, it is a false positive FP; (iii) if the cell during the simulation is not affected by a maximum debris flow depth $\geq 1.0 \mathrm{~m}$ and the event observation gives maximum a debris flow depth value $<1.0 \mathrm{~m}$, it is a true negative TN; (iv) if during the event the maximum depth flow value in the cell is $\geq 1.0 \mathrm{~m}$, it is a false negative FN. Note that for the ROC analysis the data set of maximum flow depths surveyed and calculated from the FLO-2D and TRENT-2D simulation, presented in Table 2, were extended to two other surveyed points, in order to create a more realistic data set, thereby also considering true negative conditions. Figure 9 shows a ROC graph comparing the performance in terms of $h_{\max }$ obtained by means of the application of FLO-2D and the TRENT-2D models, with a threshold of $1.0 \mathrm{~m}$ selected, showing the high accuracy of prediction of both tools. Parameters of accuracy and precision of the model results were determined, following the application of the ROC approach, as follows:

$$
\begin{aligned}
& \text { accuracy }=\frac{\mathrm{TP}+\mathrm{TN}}{\mathrm{TP}+\mathrm{FN}+\mathrm{FP}+\mathrm{TN}} \\
& \text { precision }=\frac{\mathrm{TP}}{\mathrm{TP}+\mathrm{FP}} .
\end{aligned}
$$

The accuracy values obtained are 0.88 and 0.96 respectively for the FLO-2D model and the TRENT-2D model, while the precision values are respectively 0.76 and 0.96 .

\section{Conclusions}

The simulation of the alluvial event of 1 October 2009 in Giampilieri was reproduced by means of two different models: the FLO-2D (O'Brien, 1986) and the TRENT-2D (Armanini et al., 2009). The FLO-2D model is based on a mono-phase approach, modelled through an empirical quadratic rheological relation developed by O'Brien (1986); moreover, it is not a fully 2-D model. The TRENT-2D model is fully 2-D and its two-phase rheology model is based on the dispersive pressure theory by Bagnold. Another important difference is that in FLO-2D the bed is fixed, while in TRENT-2D the bed is mobile and completely coupled with the dynamics of the mixture. On the other hand, such a model does not easily simulate the presence of unerodible zones inside the 


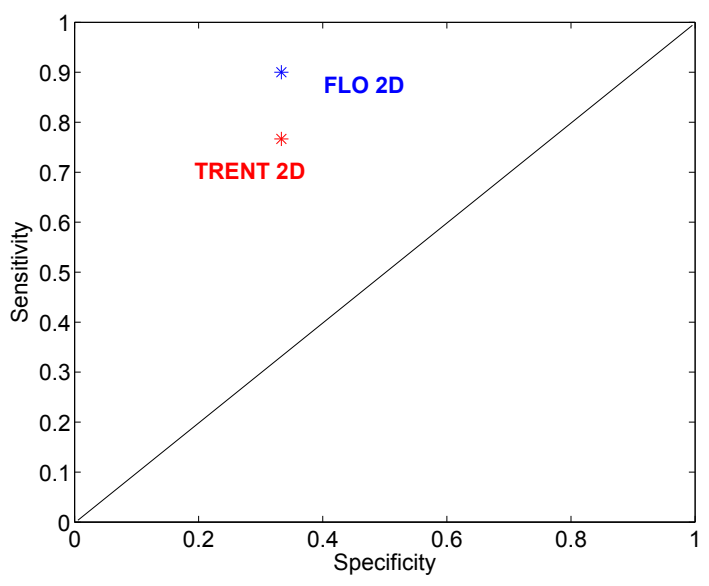

Figure 9. ROC graph related to a threshold value of $1.0 \mathrm{~m}$, evaluating the performances of FLO-2D model and TRENT-2D model in prediction of the maximum flow depth.

floodplain because it is not possible to fix the bed in some computational cells. Moreover, for the FLO-2D model, the tuning of the parameters must be done empirically, with no evidence of the physics of the phenomena. On the other hand, since the TRENT-2D parameters have a more specific physical base, it is easier to choose the right calibration values, looking for them within an acceptable physical range. The time evolution of several parameters (the deposit, the velocities, the volume of mixture involved in the event, etc.) were then systematically analysed in order to highlight the differences in the global dynamic of the event as obtained from the two codes. The results showed that both models seem capable of reproducing the depositional pattern in the alluvial fan in a fairly good manner, provided that the rheological parameters and the correct boundary conditions are assigned. In particular, FLO-2D tends to overestimate the flow depths for the reasons previously explained, while TRENT-2D slightly underestimates them. As regards the final depositions, they are slightly underestimated by both models. This is probably due to the fact that the models cannot reproduce some disturbances of the flows that occurred during the event (especially the cars, see Fig. 10), which had an important influence on the flow, as demonstrated by several videos.

Finally, FLO-2D velocities are generally higher than those predicted by TRENT-2D, due to the different rheological models. It is important to point out that accurate representation of the topography in the grid system is an essential step to obtain a reasonable replication of the observed deposition patterns. A more detailed spatial resolution of floodplain strongly improves the model results. Moreover, results may also improve if the effects of flow obstructions, such as buildings, is incorporated into the model in a proper way. Possible explanations for the inaccuracy of the model results include both systematic topographic errors or the simplification of the real multi-surge event by a single triangular hydro-

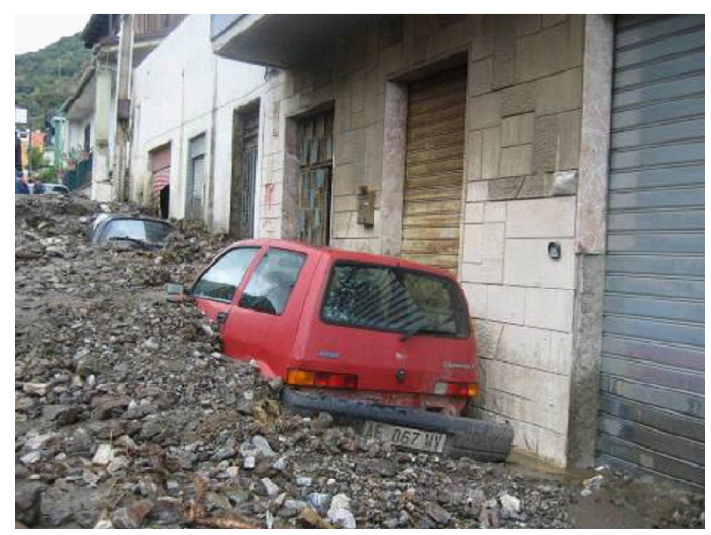

Figure 10. Street of Giampilieri village after the alluvial event of 1 October 2009. Case where the deposit material level has been influence by cars.

graph. Bed level changes either between successive surges or at the base of a flow within one surge may cause a local change in the direction of the flow. A comparative analysis of the models results (FLO-2D and TRENT-2D) has shown that the TRENT-2D model is more accurate than the FLO$2 \mathrm{D}$, although the simulation is affected by a distortion effect in evaluating the flow depth in the region of the flood area far from the main path. The determination of some statistical indicators indicates that TRENT-2D prediction is more accurate if compared with the one of the FLO-2D. Moreover, the application of the ROC approach confirms a general higher accuracy and precision of both models adopted for the simulation of the Giampilieri event, although a slightly higher sensitivity level is determined in the case of the FLO-2D when compared with TRENT-2D. Finally it can be stated that both models are good in the reproduction of the flooded area. In producing hazard and risk mapping, however, the FLO-2D is more user friendly while the TRENT-2D is more accurate.

\section{The Supplement related to this article is available online at doi:10.5194/nhess-15-735-2015-supplement.}

Acknowledgements. All consultants of the OPCM 10 October 2009 no. 3815 are greatly acknowledged for the support demonstrated and for the useful information provided. We would like to thank the Public Civil Engineering Works Office of Messina and the Department of Civil Defence of the Sicilian Region for providing important data.

Edited by: T. Glade

Reviewed by: two anonymous referees 


\section{References}

Arattano, M. and Marchi, L.: Measurements of debris flow velocity through cross-correlation of instrumentation data, Nat. Hazards Earth Syst. Sci., 5, 137-142, doi:10.5194/nhess-5-1372005, 2005.

Armanini, A., Fraccarollo, L., and Rosatti, G.: Two-dimensional simulation of debris flows in erodible channels, Comput. Geosci., 35, 5, 993-1006, 2009.

Armento, M.C., Genevois, R., and Tecca, P.R.: Comparison of numerical models of two debris flows in the Cortina d'Ampezzo area, Dolomites, Italy, Landslides, 5, 143-150, 2008.

Bagnold, R. A.: Experiments on a gravity-free dispersion of large solid spheres in a Newtonian fluid under shear, P. Roy. Soc. Lond. A, 225, 1160, 49-63, 1954.

Baum, R. L., Godt, J. W., and Savage, W. Z.: Estimating the timing and location of shallow rainfall-induced landslides using a model for transient, unsaturated infiltration, J. Geophys. Res., 115, F03013, doi:10.1029/2009JF001321, 2010.

Bertolo, P. and Wieczorek, G. F.: Calibration of numerical models for small debris flows in Yosemite Valley, California, USA, Nat. Hazards Earth Syst. Sci., 5, 993-1001, doi:10.5194/nhess-5-9932005, 2005.

Boniello, M. A., Calligaris, C., Lapasin, R., and Zini, L.: Rheological investigation and simulation of a debris-flow event in the Fella watershed, Nat. Hazards Earth Syst. Sci., 10, 989-997, doi:10.5194/nhess-10-989-2010, 2010.

Fraccarollo, L., Capart, H., and Zech, Y.: A Godunov method for the computation of erosional shallow water transient, Int. J. Numer. Meth. Fl., 41, 951-976, 2003.

Iverson, R. M., Reid, M. E., and LaHusen, R. G.: Debris Flow mobilization from landslides1, Annu. Rev. Earth Planet. Sci., 25, 85-138, 1997.

Julien, P. Y. and O'Brien, J. S.: Dispersive and turbulent stresses in hyperconcentrated sediment flows, unpublished paper, 1998.

Julien, P. Y. and Paris, A.: Mean Velocity of Mudflows and Debris Flows, J. Hydraul. Eng., 136, 967-679, 2010.
Marchi, L., Arattano, M., and Deganutti, A.M.,: Ten years of debrisflow monitoring in the Moscardo Torrent (Italian Alps), Geomorphology, 46, 1-17, 2002.

Nocentini, M., Tofani, V., Gigli, G., Fidolini, F., and Casagli, N.,: Modeling debris flows in volcanic terrains for hazard mapping: the case study of Ischia Island (Italy), Landslides, published online, doi:10.1007/s10346-014-0524-7, 2014.

O’Brien, J. D.: FLO-2D User's Manual, Version 2007.06, FLO Engineering, Nutrioso, 2007.

O'Brien, J. S.: Physical process, rheology and modeling of mudflows, $\mathrm{PhD}$ thesis, Colorado State University, Fort Collins, Colorado, 172 pp., 1986.

O'Brien, J. S. and Julien, P. Y.: Physical processes of hyperconcentrated sediment flows, in: Proc. of the ASCE Specialty Conference on the Delineation of Landslides, Floods, and Debris Flow Hazards in Utah, Utah Water Research Laboratory, Series UWRL/g-85/03, 260-279, 1985.

O'Brien, J. S. and Julien, P. Y.: Laboratory analysis of mudflow properties, J. Hydrol. Eng., 114, 877-887, 1988.

Rosatti, G., Zorzi, N., Begnudelli, L., and Armanini, A.,: Evaluation of the Trent2D Model Capabilities to Reproduce and Forecast Debris-Flow Deposition Patterns Through a Back Analysis of a Real Event, Engineering Geology for Society and Territory, 2, 1629-1633, 2015.

Takahashi, T.: Mechanical characteristics of debris flow, J. Hydraul. Div.-ASCE, 104, 1153-1169, 1978.

TRENT2D User's Manual: available at: http://simidra.com/ area-riservata/ (last access: November 2014), 2011.

Wu, Y.-H., Liu, K.-F., and Chen, Y.-C.: Comparison between FLO2D and Debris-2D on the application of assessment of granular debris flow hazards with case study, J. Mt. Sci., 10, 293-304, 2013.

Zweig, M. H. and Campbell, G.: Receiver-operating characteristic (ROC) plots: a fundamental evaluation tool in clinical medicine, Clin. Chem., 39, 561-77, 1993. 